\title{
Carotid atherosclerosis disease: A review of diagnosis, risk factors and simulations
}

\author{
Shahab Khakpour, W.A.B Wan Abas*, N.A. Abd Razak and N.A. Abu Osman \\ Biomedical Engineering Department, Faculty of Engineering, University of Malaya, Kuala Lumpur, Malaysia
}

\begin{abstract}
Cardiovascular diseases take many lives yearly and carotid atherosclerosis disease is responsible of a significant portion of cardiovascular deaths. Carotid atherosclerosis disease is a multi-aspects disease and only by considering all of its aspects, a comprehensive insight can be achieved whereas near all of researchers which have been conducted to study, cover only one or two aspects of carotid atherosclerosis disease. Current review by summarizing and categorizing of 77 selected literatures which were published in different scopes of carotid atherosclerosis disease, have attempted to present a comprehensive and succinct source for further studies and fill the gap between carotid atherosclerosis disease aspect by presenting them coincidently. In this review, usage of common diagnostic methods such as ultrasonography and magnetic resonance imaging in carotid atherosclerosis disease detection have been discussed. Also, Current review shows that carotid atherosclerosis disease is product of combination of biochemical, biomechanical, diseases and human health-related risk factors. Also, high concentration of low density lipoprotein seems to be carotid atherosclerosis disease trigger. In addition, carotid atherosclerosis disease simulations indicate that regions which are prone to carotid atherosclerosis disease are associated with low and oscillatory wall shear stress and recirculation zone. It appears that collaboration of different scopes of carotid atherosclerosis disease can lead to outstanding results and using realistic data in carotid atherosclerosis disease studies leads to more accurate results.
\end{abstract}

Abbreviations: 2D: Two Dimensional; 3D: Three Dimensional; AP: Atherosclerotic Plaque; B-Mode: Brightness Mode; CA: Carotid Artery; CAD: Carotid Atherosclerosis Disease; CAP: Carotid Atherosclerotic Plaque; CAS: Carotid Artery Stenosis; CCA: Common Carotid Artery; CT: Computational Tomography; CVA: Cerebrovascular Diseases; CVD: Cardiovascular Diseases; DS: Doppler Sonography; ECA: External Carotid Artery; EDV: End Diastolic Velocity; FEA: Finite Element Analysis; FEM: Finite Element Method; FSI: Fluid Structure Interaction; GI: Global Importance; HDL: High Density Lipoprotein; HDL-C: High Density Lipoprotein Cholesterol; hs-CRP: High sensitivity C-reactive Protein; ICA: Internal Carotid Artery; IMT: Intima Media Thickness; LDA: Laser Doppler Anemometer; LDL: Low Density Lipoprotein; LDL-C: Low Density Lipoprotein Cholesterol; Lp-PLA2: Lipoprotein-associated Phospholipase A2; MRI: Magnetic Resonance Imaging; NLR: Neutrophil to Lymphocyte Ratio; NMR: Nuclear Magnetic Resonance; PAD: Peripheral Artery Disease; PDI: Power Doppler Imaging; PLR: Platelet to Lymphocyte Ratio; PM: Plaque Morphology; PR: Plaque Rupture; PSV: Peak Systolic Velocity; Re: Reynolds Number; RT: Radiotherapy; RF: Reversal Flow; RZ: Recirculation Zone; SI: Shear Index; TF: Transfer Function; TG: Triglycerides; TIA: Transient Ischemic Attack; US: Ultrasonography; WNS: Wall Normal Stress; WSS: Wall Shear Stress

\section{Introduction}

Carotid artery role (supply oxygenated blood to the brain) in cerebrovascular system is momentous and therefore CA malfunctions and its diseases have been considered by medical scientists, biochemists and biomechanists. One of the most prevalence CA disease is CAD which is defined as CA lumen narrowing (or occlusion) due to arterial wall distension. Untreated CAD generally leads to ischemic stroke, TIA, permanent injuries and death. Over 750000 people are victims of stroke just in USA yearly [1] and CAD solely is cause of approximately $10 \%$ [2] to $20 \%$ [3] of all ischemic strokes in world.
Among human arterial system, CA is one of the most prone arteries to atherosclerosis disease. Complex CA geometry and consequently chaotic blood flow regime of CA (by rising LDL concentration) make it disposed to CAD [4]. It is assumed that collaboration of several factors (biochemical, biomechanical, life style, age etc.) is cause of CAD. Cerebrovascular biomechanists think that AP formation and progression are associated with low WSS [5] and high oscillatory WSS [6] regions. Scientists believe that increment in LDL concentration [5] leads to penetration of excessive levels of LDL particles to subendothelial layer $[7,8]$. Then, LDL particles become oxidized and reaction between oxidized LDL particles and immune system ends to formation of foam cells. Finally, accumulation of foam cells between intima and medial layers brings about intima swelling [9]. Beside biochemical and biomechanical causes, CVD and external factor such as tobacco smoking, diabetes, age and gender contribute in CAD progression [1].

CAD does not happen suddenly and is a time consuming procedure [9] but in many times, it symptoms reveals in final stages of the disease. CAD can be classified in two subgroups: 1) symptomatic and 2) asymptomatic. Most of CAD patients have not obvious symptoms and asymptomatic CA is accounted as a public health issue [10] and usually after formation of mild and sever stenosis (50\% and above) symptoms can be observed. Therefore, researchers are keen to understand CAD mechanisms before CAD turns to symptomatic goes to critical stages. So, Cardiovascular experts prefer to control and

Correspondence to: W.A.B Wan Abas, Professor, Biomedical Engineering Department, Faculty of Engineering, University of Malaya, 0603 Kuala Lumpur, Malaysia, Tel: +603-79674581, +603-79674579; E-mail: drirwan1@um.edu.my

Key words: carotid artery disease, risk factor, diagnosis, simulation, stenosis

Received: August 08, 2016; Accepted: August 19, 2016; Published: August 23, 2016 
treat CAD at early stages by using medication [1], prescribing diet and preventing unhealthy life style [11] but in acute CAD (high severity of lumen reduction (>70\%) [2] or occlusion), usually invasive surgeries for AP removal or artery lumen delamination such as endarterectomy and stenting must be perform. The risk of stroke, heart attack, or death in these surgeries is low [1] but in cases which patient are too old or sick, further consideration should be performed.

Some of cerebrovascular scientist have attempted to diagnoses, determine and simulate CAD. As symptomatic CAD treatment usually implies invasive operations, cerebrovascular researchers have done many study to found reliable risk factors of CAD and implement them in asymptomatic CAD stages. The scope of CAD risk factors are vast and includes biochemical, biomechanical, CVD (and related surgeries), non-CVD treatments and other risk factors.

Many PM and AP localization studies have been performed by cerebrovascular researchers $[4,12,13]$ to help cerebrovascular surgeons to select best treatment method and strategies. Therefore, many diagnostic methods (such as US, MRI, CT imaging and old age etc.) have been implemented to assess CAP but usefulness and application of these methods should be consider carefully to select most cost effective diagnostic tools for CAD patient $[14,15]$.

It should be noticed that the border between CAD diagnosis and CAD risk factor determinations extremely narrow and can be used instead of each other. For example, Sidhu and Allan [16] by using Doppler US (which is used for detection of CAS), have introduced some PSVs and EDVs which are associated with AP severity. These results can be used either as CAD risk factor in a general health checkup or as CAD diagnostic criteria in detection of asymptomatic CAD.

CA behaviors study and AP localization in vivo seems so hard and nowadays, due to high speed computers and high tech tests, cerebrovascular and hemodynamics scientists prefer to study CAD in vitro or numerically. Some researchers (by considering CA and blood as a channel-fluid model) have tried to investigate CAD mechanisms mechanically $[6,13,17]$.

The aim of this review is provide a comprehensive and succinct source which includes $\mathrm{CAD}$ related literatures and presenting a coherent insight into CAD diagnoses, risk factor determination and simulation simultaneously. It seems there is a gap between (biochemical, biomechanical, medical and lifestyle) aspects of CAD and near all of papers published in this scope, have considered only one or two of these aspects. Whereas, CAD aspects are linked together strictly and only by considering them coincidentally, a conceptual understanding of CAD becomes possible. For instance, scientists only by using diagnostic tools (Such as US, MRI, pathological tests etc.) are able to measure CAD risk factors and detect CAD risk factors or biomechanical researchers solitary by applying realistic loads and conditions (obtained from mechanical testing, US, MRI etc.) can obtain precise data and some hemodynamical features of flow (such as low WSS) can be used in risk factor determination and diagnoses of CAD. This review is begun with CAD diagnostic methods investigation and then CAD risk factors will be introduced and finally, numerical simulations which have done in atherosclerosis area (especially CA) will be mentioned.

\section{1-CAD diagnosis methods}

Acquiring hemodynamical parameters, arterial wall properties and plaque composition precisely are the keys of comprehension of atherosclerosis progression and regression mechanism and medical or mechanical diagnostic tools assist scientists in such cases.
As blood caries near all of CAS risk factor, blood rheological studies can be very helpful to detect atherogenic regions. For example, existence of RZ, low WSS and high oscillating SI are associated with atherosclerosis progression and extension in CA [18]. Also, studding mechanical properties and mechanisms of arterial wall seems promising steps toward identifying how AP forms and AP reactions under blood loading. In addition, AP composition is very different from arterial wall and therefore reaction of APs to exerting forces are dissimilar to arterial wall and therefor PM can be implemented by scientist to discover AP rupture mechanism. Study of blood flow behavior and detecting arterial wall and AP properties in CAD, needs to usage of diagnostic tools such as CT scan, MRI, angiography, LDA, PDI, US elastography, spectroscopy, pulsed or colored DS and other conventional pathological tests. Sonography is known as a noninvasive, fast, reliable and cost-effective method to diagnoses of CAS. CA sonography can be done in many ways and technics such as B-Mode, PDI and DS.

Bluth [14] has been studied implementation of common sonography methods in CAS detection. He stated that the complete duplex examination, although accurate, is too long and complicated and should be used as final test before carotid intervention. Also, $\mathrm{He}$ mentioned that 3D Doppler US instruments cannot be found even in some well-equipped sonography centers. He claimed that PDI is the most cost-effective method among common sonography methods and thought to be more independent of angle than standard color DS. Steinbach et al. [19] have tried to use standard B-Mode sonography (very feasible and cost-effective method) insist of radiofrequency recording to detect symptomatic CAS. Their outcomes revealed that B-Mode method shows sufficient accuracy and precision to determine morphological and physiological properties of arterial wall in symptomatic patients but wave form details may be invisible in this approach and cannot be used for advanced proposes. Pandya and Gupta [10] suggested that using duplex US studies at first step and then using angiography (as second-line exam) can be helpful to reduce the number of false-positive CAS findings. They mentioned that risk of angiography is relatively high and could be replaced by other invasive test such CT angiography or MR angiography. Den Hartog et al. [15] have focused on MRI methods for plaque characterization of CAS. The reviewed articles by them covered $3.0 \mathrm{~T}$ and $1.5 \mathrm{~T}, 2 \mathrm{D}$ and 3D T1-weighted researchers. They announced adjusted MRIs (moderate-to-good sensitivity and specificity) can be employed in identification of plaque inter-hemorrhage, calcification, fibrous cap and lipid-rich necrotic core. It should be mentioned that beside US, MRI and angiography, other diagnostic methods such as CT imaging, computer aided analysis and mechanical tests are common in diagnosis CVA such as CAS.

\section{Hemodynamics-based diagnosis}

Some researchers such as Sidhu and Allan [16] have considered usage of US to estimate hemodynamical parameters such as PSV for AP detecting. Sakamoto et al. [20] examined two different sonography technics: pulse wave and continuous wave sonography to assess the best method to measure PSV. They applied the conventional angiography as a criterion. Their works showed that continues wave Doppler appears to have better inter-rater reproducibility than pulse wave DS in assessing high PSV. Sidhu and Allan [16] have reviewed application of US in ICA AP detection. They have suggested certain PSV and EDV (hemodynamical properties) to determine severity of ICA AP. For example, they have concluded that PSV $>130 \mathrm{~cm} / \mathrm{s}$ and $40 \mathrm{~cm} / \mathrm{s}<\mathrm{EDV}<100 \mathrm{~cm} / \mathrm{s}$ are associated with $\% 60-\% 69$ ICA lumen 
reduction. Also, in a recent and novel investigation, Tokunaga et al. [21] have introduced a standard to determine severity of stenosis from PSV thresholds in ICA. They precisely announced $130 \mathrm{~cm} / \mathrm{s}, 160 \mathrm{~cm} / \mathrm{s}$, $200 \mathrm{~cm} / \mathrm{s}$, and $270 \mathrm{~cm} / \mathrm{s}$ PSV corresponding values for ICA stenosis severity $\geq 50 \%, \geq 60 \%, \geq 70 \%$, and $\geq 80 \%$ respectively. In another research, Masuda et al. [22], by arterial tree segment-modeling, have shown that beside PSV, second PSV at common carotid is a diagnostic factor for CAS. They announced that measuring of CA flow velocity waveform reveal that there is a relationship between elasticity of CCA and PSV+ second PSV. In another research, Poepping et al. [23], in a similar study, by using pulsed-DS have investigated hemodynamic role in stroke risk and announced RZ and paths of high-velocity jets are completely dissimilar in different stenosis eccentricity (but the same severity). Also, they reported flow turbulence intensity is highly elevated near sever stenosis. They suggested that researchers should pay more attention to plaque shape beside its severity.

Some researchers such as Gijsen et al. [24], have studied hemodynamical parameters of blood flow flied in stenosed CA by using another techniques such as LDA. They implemented LDA for largescale study of axial flow flied. Their results revealed that there is a shear layer at non-divider wall of carotid bifurcation where is associated with vortex formation at deceleration phase of cardiac cycle and by adding mild stenosis, stability of flow will be changed and instability at shear layer leads to flow disturbance. They concluded that using large-scale features of flow field (by using LDA or MRI or DS) to detect carotid stenosis clinically is a very difficult issue.

\section{Elasticity-based diagnosis}

Understanding mechanical properties of arterial wall can help to realize CAS formation procedures and further simulations. Arterial wall consists of three layers (intima, media and adventitia) and APs take form between these layers. Therefore assessing biomechanical properties of arterial wall and AP can help to detection of AP. As AP composition is very different from healthy atrial wall, abnormal elastic moduli can be used as a sign of CAS.

Huang et al. [25] have claimed that pulse wave velocity (by using distension waveforms) might be implemented as a hopeful index for arterial stiffness characterization and hypertension management. Kamenskiy et al. [26], by using B-mode Duplex US and angiocatheter, have attended to study circumferential stress and tangent elastic moduli of CCA, ICA and ECA in vivo. They concluded the quality of biomechanical features of CCA, ICA and ECA is similar but they are dissimilar in quantity. Also, they mentioned that circumferential stress and tangent elastic moduli are nonlinear. They reported circumferential stress from end diastole to peak systole from $25 \pm 7 \mathrm{kPa}, 22 \pm 7 \mathrm{kPa}$ and $28 \pm 8 \mathrm{kPa}$ to $63 \pm 23 \mathrm{kPa}, 57 \pm 19 \mathrm{kPa}$ and $67 \pm 23 \mathrm{kPa}$ for CCA, ECA and ICA respectively. In addition, nonlinear tangent elastic modules from end diastole to peak systole vary from $0.40 \pm 0.25 \mathrm{MPa}, 0.49 \pm$ $0.34 \mathrm{MPa}$ and $0.68 \pm 0.31 \mathrm{MPa}$ to $1.50 \pm 2.05 \mathrm{MPa}, 1.14 \pm 0.52 \mathrm{MPa}$ and $1.51 \pm 0.69 \mathrm{MPa}$ for CCA, ECA and ICA respectively. Golemati et al. [27] have attempted to develop a novel way for detection of vulnerable asymptomatic CAS by using US. They had assumed that the texture of arterial wall at the boundary between arterial wall and plaque shoulder can be representative of high severity stenosis existence. Their results have shown that there is discontinuity between arterial wall and plaque shoulder texture and it can be used as a marker for detection of vulnerable tissue which can lead to rupture.

\section{PM-based diagnosis}

Critical or mild severity of AP can be achieved by PM and AP mechanical behavior. Many researchers have spent many time to study PM and discovering of its biomechanical properties. It is because of by understanding mechanical behavior of plaque, risk factor determination of PR and preventing of stroke. As AP composes from several material such as lipid and spotty calcification, detection of accurate plaque mechanical behavior seems a complicated task. Recently, Nieuwstadt et al. [28], in a novel method (inverse simulating), have mixed MRI, ultrasound elastography and FEA methods together to estimate plaque and arterial wall elasticity. They assumed that plaques have lipid-rich necrotic core and used noe-Hookean model for elasticity modeling. They have started their research by composition of a ground truth model from nine $2 \mathrm{D}$ carotid plaque specimens extracted from endarterectomy. Then, they used this ground truth model in inverse FEA and produced simulated US elastogram and MRI and by comparing them, they introduced an estimation for plaque and arterial wall elasticity. They have reported wall elasticity $128.9 \pm$ $24.8 \mathrm{kPa}$ and lipid-rich necrotic core plaque $8.5 \pm 4.5 \mathrm{kPa}$. In similar approach, Chai et al. [29] have implemented inverse FEM to determine anisotropic (instead of isotropic simplification assumption) properties of human CAS plaque by using micro indentation tests. They have used an inverted microscope and digital images correlation to derive finite element model for further studies on collagen fiber deformation perpendicular to indentation direction (middle of the fibrous cap, shoulder of the cap, remaining intima tissue) and claimed that fiber stiffness and dispersion are independent of indentation location. Their results showed that plaque tissue is extremely anisotropic and near plaque shoulder, plaque is stiffer than maximum stenosis region. Their results indicated that the level of non-linearity between intima tissue and shoulder caps of plaques is significantly different and this discontinuity may lead to experience higher strains on high blood pressure and consequently PR. Their study confirm Golemati research results.

By obtaining mechanical properties of AP, CAS can realize directly. Barrett et al. [30] have implemented uniaxial extension tests and micro CT to focus on mechanical stretching mechanism of CAP tissue. They used 17 CAPs obtained from endarterectomy and applied uniaxial extension force to reach circumferential failure. They used high resolution CT imaging to observe calcification morphology of CAP ruptured and electron microscopy to find mechanically ruptured and calcified and non-calcified boundary regions. They realized that CAPs can be categorized to four groups by calcification pattern: 1) speckled, 2) diffuse tissue, 3) concentric and 4) diffuse necrotic core and expansion mechanical properties of plaque are influenced by calcification patterns.

In another study done by Heiland et al. [31], viscoelastic parameters of CAS plaque were investigated to determine risk of PR numerically and experimentally. They used nine CA plaques (obtained from endarterectomy) and healthy CA section and by using a novel in-vitro mechanical testing protocol, have produced high fidelity and low fidelity finite element models. Then, they applied mechanical forces which were obtained in mechanical testing to obtain Load-displacement curves. Their results showed strain stiffening and viscoelasticity properties for healthy and stenosed CA. Their simulation outputs were in good agreement with mechanical testing but they stated because of highly nonlinear elasticity of arteries, initial conditions (in numerical simulation) can have great influence on parameters estimation.

\section{Other diagnostic methods}

Some of cardiovascular scientists have attempted to combine non- 
conventional approaches to accepted methods to reach to faster and more reliable CAS detection.

Recently, Xiao et al. [32] through a promising investigation, have concentrated on TF usages in artery stenoses detection. They modeled human arterial tree as a 55 segments transmission line model and studied location and severity of pre-allocated (in carotid, aorta and iliac arteries) stenosis on TF. They built a real-condition finite element model based on data obtained from TF database and support vector machine to diagnose artery stenosis. Their results showed that supposed model is able to determine location and severity of stenosis by satisfactory accuracies. They claimed that their proposed method of combining TF and support vector machine is a theoretically feasible method for diagnosis of artery stenosis. Also, some researchers such as Bonanno et al. [33] combine two or more method to detect location and severity of CAP. Bonanno et al. combined US (echogenicity features) and computer aided diagnosis techniques (image processing) to generate an automatic diagnostic system for detecting location and severity of CAP. They announced that their proposed system is independent of operator mistakes and able to detect and classify CAP. Diagnostic methods and propose of their implementation are summarized in table 1.

By detection of $\mathrm{CAD}$, cerebrovascular experts should make a wise decision as soon as possible. Recently, Chaturvedi and Sacco [2] considered different treatment strategies applied to patient with ICA stenosis. They have suggested new comprehensive approach for treatment of symptomatic and asymptomatic ICA stenosis (Figure 1). Also, they indicated that TIA or stroke are not the solely criteria for symptomatic assumption of CAS and cognitive impairment should be counted in CAS symptoms.

As can be seen in table 1, there are many choices to select CAD diagnostic methods and among those, US are more common. US methods are well developed for CAS detection and in some cases are capable to combine with other techniques such as MRI or image processing. Implying US in CAS detection is cost effective and between US techniques, PDI is suggested.

\section{2-CAD risk factors}

Many methods have been introduced by scientist to determine CAD but they can be categorized in four groups: 1) Biochemical, 2) Biomechanical and 3) CVD, treat-related and vital signs and 4) common risk factors. In some cases, there is more than one risk factors and it should be noted that existence of one or more CAD risk factors could be considered as a stronger CAD risk factor.

\section{Biochemical risk factors and vital signs}

Biochemical risk factors and vital signs usually are used by medical scientists to determine existence, progression or regression of CAD. One of the most important chemical CAD risk factors is LDL high concentration $[5,9,17]$ in CA (especially at sinus and siphon of ICA $[16,21,34])$. Therefore, knowledge about high LDL concentration regions where are prone to atherosclerosis, can be helpful in determining CAD. However, some researchers have stated that LDL high concentration is not precise risk factor for CAD. Park et al. [35] have reported a case that a patient had low LDL-C without medication but after carotid ultrasonogram and coronary angiograms, stenosis were seen at both carotids, mid left anterior descending artery and mid diagonal artery. Recently, Amor et al. [36] have investigated relationship between atherogenic dyslipidemia (elevated levels of TG and LDL and low levels of HDL-C) and CAS as a risk factor in newlydiagnosed type- 2 diabetic patients. They implemented B-mode US and NMR spectroscopy to assess IMT and existence CAP. They stated that triglyceride-rich lipoproteins may have distinct role in atherosclerosis disease and suggested that type-2 diabetic patients should be checked by modern methods such as NMR-assessed advanced lipoprotein profile.

Table 1. CAD diagnostic methods

\begin{tabular}{|c|c|c|}
\hline Researchers & Diagnostic Methods & Purpose of study \\
\hline Pandya \& Gupta [10] & Duplex US & Reducing the number of false-positive CAS findings \\
\hline Bluth [14] & Doppler US, PDI and standard color DS & $\begin{array}{l}\text { Implementation of common sonography methods in detection CAS } \\
\text { (PDI is Suggested) }\end{array}$ \\
\hline Den Hartog et al. [15] & MRI & Detecting of best MRI setting for plaque characterization of CAS \\
\hline Sidhu and Allan [16] & PSV and EDV (US) & Determine severity of ICA plaque \\
\hline Steinbach et al. [19] & Standard B-Mode sonography & Detection of symptomatic CAS \\
\hline Sakamoto et al. [20] & Pulse wave and continuous wave sonography & Detection of best method to measure PSV (for using in CAS detection) \\
\hline Tokunaga et al. [21] & PSV (US) & Measuring of ICA stenosis severity \\
\hline Masuda et al. [22] & PSV and second PSV (US) & Detection of CAS \\
\hline Poepping et al. [23] & Pulsed-DS & Study hemodynamic role in stroke risk \\
\hline Gijsen et al. [24] & LDA & Large-scale study of axial flow flied in CA \\
\hline Huang et al. [25] & US & $\begin{array}{l}\text { Implementation of pulse wave velocity in arterial stiffness characterization } \\
\text { and hypertension management }\end{array}$ \\
\hline Kamenskiy et al. [26] & B-mode Duplex US and angiocatheter & $\begin{array}{l}\text { Determination of circumferential stress and tangent elastic moduli of } \\
\text { CCA, ICA and ECA }\end{array}$ \\
\hline Golemati et al. [27] & US & Risk factor determination of vulnerable asymptomatic CAS \\
\hline Nieuwstadt et al. [28] & MRI, US elastography and FEA & Inverse simulation of plaque and arterial wall elasticity estimation. \\
\hline Chai et al. [29] & $\begin{array}{l}\text { Inverse FEM, microscope and } \\
\text { digital image }\end{array}$ & Determination of anisotropic CAP \\
\hline Barrett et al. [30] & Uniaxial extension tests and micro $\mathrm{CT}$ & Understanding of mechanical stretching mechanism of CAP tissue \\
\hline Heiland et al. [31] & Mechanical testing and FEM & Acquiring viscoelastic parameters of CAS plaque \\
\hline Xiao et al. [32] & TF and support vector machine & Risk factor determination of location and severity of AP \\
\hline Bonanno et al. [33] & US and image processing & $\begin{array}{l}\text { Generating an automatic diagnostic system for detecting location and } \\
\text { severity of CAP }\end{array}$ \\
\hline
\end{tabular}

It shows CAD diagnostic methods and propose of implementation of them in CAD. 


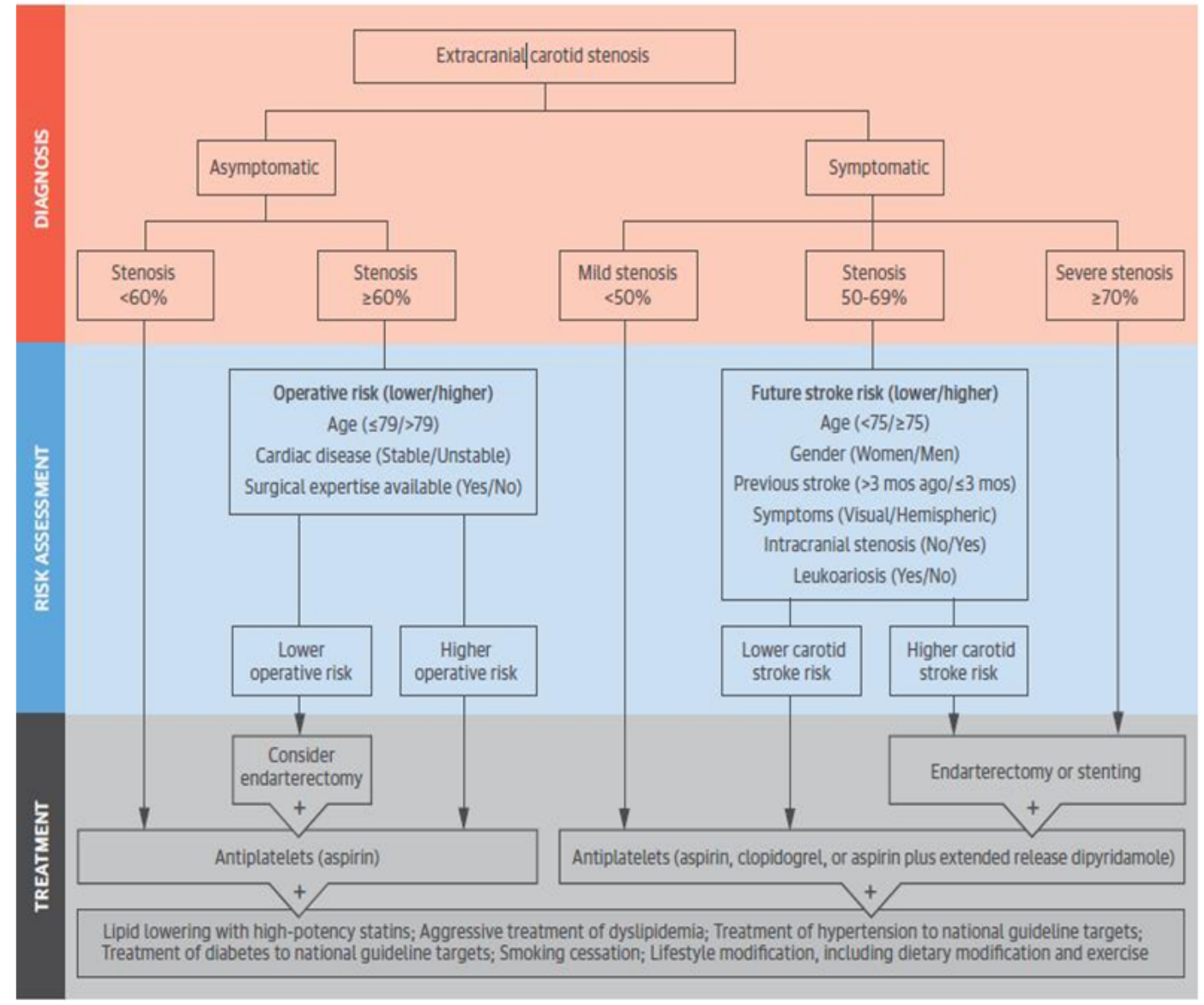

Figure 1. CAS treatment strategy by Chaturvedi et al. [2].

Sander et al. [24] have reported that high values of Glycohemoglobin (Hemoglobin A1c) and $\mathrm{C}$ - reactive protein are strongly associated with existence of subclinical CAD. In another study, Huang et al. [37] have mentioned hs-CRP as a biochemical marker for atherosclerosis. They released their study outputs on 5349 Chinese (older than 40 years) participants in order to study correlation between hs-CRP levels and asymptomatic CAS. They concluded hs-CRP is associated with asymptomatic CAS in male and older people and can be used as a CAD predictor.

Hyun et al. [38] have mentioned many other biochemical CAD risk factors such as interleukin-6, and tumor necrosis factor-alpha and stated such biochemical risk factors are very hard to obtain in clinical practices. They have introduced NLR as a suitable marker for CAD. Also, they declared NLR can be a clinically significant risk factor of the severity of carotid stenosis in male patients with ischemic stroke. In another related study, Köklü et al. [39] investigated the correlation of NLR and the risk of stroke in patients with intermediate CAS. They concluded NLR is associated with intermediate CAS and increasing NLR in an independent variable for CAS to turn in to symptomatic. Also, PLR is known as a new biochemical marker for CAD severity determinations. Varim et al. [40] explored the relationship between PLR and CAS in 140 patients and stated PLR values may be associated with critical stenosis in at least one of the carotid arteries. Therefore, PLR values can be used to predict CAS. Recently, relationship between plasma levels of Lp-PLA2 and server CAS was investigated by SarlonBartoli et al. [41]. They indicated incremented circulating Lp-PLA2 can
Table 2. CAD biochemical risk factors.

\begin{tabular}{|l|l|}
\hline Researchers & Biochemical Risk factor and vital sign \\
\hline Sander et al. [24] & High Glycohemoglobin and CRP \\
\hline Park et al. [35] & High Concentration LDL-C \\
\hline Amor et al. [36] & Dyslipidemia (Type-2 diabetic) \\
\hline Huang et al. [37] & High hs-CRP \\
\hline Hyun et al. [38] & $\begin{array}{l}\text { High NLR, interleukin-6, and tumor } \\
\text { necrosis } \\
\text { factor-alpha, C-reactive Protein }\end{array}$ \\
\hline Varım et al. [40] & High PLR \\
\hline Sarlon-Bartoli et al. [41] & High Lp-PLA2 \\
\hline Kakkos et al. [42] & High serum creatinine, Hyperlipidemia \\
\hline
\end{tabular}

be used as a biochemical risk factors to determine unstable plaque and high severity CAS. In another study, Kakkos et al. [42] introduced high serum creatinine as a biochemical risk factor of CAS progression.

$\mathrm{CAD}$ and atherosclerosis biochemical risk factors have been developed considerably and cerebrovascular scientist are using them. Beside biochemical risk factors, vital sign can help cerebrovascular surgeons to determine that which patients need to further diagnosis but vital sign can be interpreted wrongly and should be used as a side risk factor (biochemical risk factors and vital sign are summarized in table 2).

\section{Biomechanical risk factors}

Beside biochemical markers, CAD biophysical risk factors can 
be implemented in CAS detection and assessments. Biomechanical risk factors are related to mechanical properties of arterial wall and hemodynamics.

The Most well-known physical CAD risk factor is IMT. IMT strongly is affected by biochemical (such as LDL) and rheological risk factors (such as WSS). IMT (and consequently CAS) association with Low WSS, high oscillatory WSS and RF is reported by many researchers $[5,17,43,44]$. For instance, at an early research done by Gnasso et al. [45], coronary heart disease risk factors (such as HDL-C) effects on IMT has been investigated. They concluded that in multiple regression analysis, IMT was strongly and significantly associated with the presence of CAS. Also, Boulos et al. [46] have used carotid IMT as a well-established risk factor of atherosclerosis in their study. They stated carotid IMT increases by age. However, some researchers such as Spence et al. [47] are believed that IMT role in risk factor determination of CAS should be revised and other features ought to be considered. They stated IMT, stenosis and plaque are biologically and genetically distinct phenotypes of atherosclerosis. Spence et al mentioned that CAPs unlike coronary atherosclerotic plaques (which are diffuse) are focal and they suggested that measurement of total plaque area is more strongly predictor of stroke, death or myocardial infarction than is IMT. They emphasized AP grows along the CAS 2.4 times faster than they thicken, so measuring plaque is more sensitive than measurement of IMT for assessing the efficacy of therapy for atherosclerosis and all carotid and coronary plaques should not called as atherosclerosis and it is better to classified them as IMT, stenosis or plaque.

CA geometry plays major role in hemodynamic and consequently have great influences on plaque formation. Arteries which have complex geometry such as ICA and aorta are more prone to atherosclerosis than other arteries. Goubergrits et al. [48] have casted 31 specimens from 23 carotid autopsy and have studied geometry influences on formation of CAP. Their efforts to find a correlation between CA geometry and CAP location showed that ICA and ECA are more prone to advanced CAD $(>\% 70$ lumen reduction) and angle of bifurcation has not significant effects on CAP formation. They introduced ICA sinus enlargement (> 1.2 times of CCA lumen) is the most notable geometrical risk factor. In another investigation, Zhang et al. [44] have performed a numerical study to find the correlation between ICA geometry and regions prone to CAS. They assumed that atherogenic regions are associated with low WSS and high oscillatory SI and classified ICAs to 4 groups (S, U, V and $\mathrm{C}$ shape). They have reported siphon inner and outer bends of ICA as most prone site to atherosclerosis and introduced three critical sites in these regions. They stated that possibility of progression of CAP in outer band of V-shape ICA are less than other shapes. Also, C shape ICA due it's out of plan curvatures experiences higher WSS and lower oscillatory SI and consequently is less suspected to atherosclerosis than $\mathrm{V}$ and $\mathrm{U}$ shapes in second curvature of ICA. They suggest ICA shape as ICA stenosis risk factor. Also, Sharifi and Niazmand [49] applied realistic boundary conditions on human carotid model to investigate numerically the Non-Newtonian blood assumption effects on LDL accumulation at siphon of ICA. They reported the geometrical shape (V, C or U type CA) as a very important factor for CAD risk factor determination and in contrast to common belief, Non-Newtonian assumption is vital for determining the atherogenesis regions in large arteries.

Hemodynamical parameters such as low WSS, Oscillating WSS, altering shear stress and RZ (which are known to be associated with IMT) are another type of biomechanical CAD risk factors. Some researchers such as Massai et al. [50] and Gallo et al. [43] have implemented shear stress and WSS in their researches as a CAD indicator. Massai et al. [50] introduced fluctuating and abnormal shear stress as possible cause of platelet activation and aggregation in CAD. Also, Gallo et al. [43] mentioned low WSS and high oscillatory WSS as biomechanical localizing factor of vascular dysfunction. Their study revealed that RF, low axial component of WSS and high Oscillatory WSS are co-localized at carotid sinus (high Non-axial component WSS does not happen at this site) where is highly prone to CAD.

Kakkos et al. [42] have showed that by $\mathrm{PM}$, progression and regression of asymptomatic $\mathrm{CAD}$ is feasible. Their investigations showed high grades of stenosis, younger age, absence of discrete white areas in the plaque, and taking lipid lowering therapy were independent basic risk factors of increased incidence of regression and high serum creatinine, male gender, not taking lipid lowering therapy, low grades of stenosis, and increased plaque area were independent baseline risk factors of progression.

Biomechanical risk factors (similar to biochemical risk factors) needs to measurement and diagnostic methods such as US and MRI should be used. Biomechanical risk factors are briefly represented in table 3.

\section{CVD, non-CVD and treat-related risk factors}

Researchers believe CAD is related to CVD and treat-related methods. Cardiovascular/ cerebrovascular systems work like a complicated network and one perturbation in this system may lead to a CVD or CVA in other part of this network. As were reported by researchers, many CVD and non-CVD diseases such as hypertension, hyperlipidemia, and diabetes are able to trigger CAD. Sobieszczyk [1] in an article, has investigated CAS causes and treatments. He has introduced hypertension and diabetes as a critical CAD risk factor. $\mathrm{He}$ has mentioned that there are strong evidences that show hypertension rises up arterial wall lipid infiltration rate and consequently increases risk of CAS. Tobacco smoking are related to many CVD. Smoking damages the lining of the blood vessels and makes cholesterol deposits more likely to form [1]. In another research, Joh et al. [51] introduced old age, hypertension and tobacco smoking as most important risk factor of CAD.

Diabetes is associated with hypertension and hyperlipidemia and diabetic penitents are more prone to cholesterol blockage in their arteries [1]. Vouillarmet et al. [52] observed the progression of $\mathrm{CAD}$ in diabetic patient and reported that there positive relationship between diabetes and carotid AP formation. Also, they announced that the benefit of a systematic follow-up of carotid atherosclerosis seems limited.

In many cases, pervious CVD may lead to regression or to another

Table 3. CAD biomechanical Risk factor.

\begin{tabular}{|l|l|}
\hline Researchers & Biomechanical Risk factor \\
\hline Kakkos et al. [42] & $\begin{array}{l}\text { Low grades of stenosis, increased plaque area } \\
\text { (progression risk factors) }\end{array}$ \\
\hline Gallo et al. [43] & $\begin{array}{l}\text { Low WSS, high oscillatory WSS and reversal } \\
\text { flow }\end{array}$ \\
\hline Zhang et al. [44] & C shape ICA \\
\hline Gnasso et al. [45] & Increment in IMT \\
\hline Boulos et al. [46] & Increment in IMT (By old age) \\
\hline Spence et al. [47] & High total plaque area \\
\hline Goubergrits et al. [48] & ICA sinus enlargement (>1.2 times of CCA lumen) \\
\hline Sharifi and Niazmand [49] & Existence of In plane curvature (ICA) \\
\hline Massai et al. [50] & Abnormal shear stress \\
\hline
\end{tabular}


CVD. Strömberg et al. [53] studied risk of early recurrent stroke in symptomatic high grade CAS and stated this risk is not high as mentioned earlier by other researchers but exist. In high grade CAS, risk of PR and hemorrhage due to high WSS and blood pressure at systolic phase is high. In this situation, after hemorrhage and coagulation, the artery lumen reduces and therefore, risk of stroke increases. Teng et al. [54] have mentioned in their research output that there is a strong correlation among plaque hemorrhage and cerebrovascular events. They suggested to pay more attention to PM then other pathological criteria. Also, Razzouk et al. [55] have investigated the relationship between PAD and CAD. Their study revealed even at tremendously low symptoms, existence and severity of PAD and CAD are associated with each other. In a similar study, Alexandrova et al. [56] have studied prevalence and severity of symptomatic CAD in patients suffering PVD by using US. Their results showed that near \%0.25 of PVD patient cohort have symptomatic or asymptomatic (symptomatic to asymptomatic ratio was 0.305) CAD. They stated among CAD and PVD risk factors, male gender and having stroke or TIA experiences are the strongest ones.

Sometime, treatment of cardiovascular disorders may result in regression or another diseases. For instance, Steinvil et al. [57] stated that there is concomitant among CAD and coronary atherosclerosis diseases. They showed relationship between severity of CAS and extent of coronary atherosclerosis are coherent [58] and blood rheology and PM may be different after stenting. Iannaccone et al. [59] studied CAD after stenting numerically. They used lumen gain and WSS as causes of stenting failure and concluded that a CAS with elliptic lumen shape and a thinner fibrous cap with an underlying lipid pool result in higher stenosis reduction, while large calcifications and fibrotic tissue are more prone to recoil. In a similar study, Rosa et al. [58] have studied the commonness of CAD and usage of CAD as a death risk factor for patient undergoing coronary artery bypass grafting. They have discovered that a high prevalence CAD exists among coronary artery bypass grafting patients and chronic renal failure is a mortality independent factor. It can concluded that coronary artery diseases and $\mathrm{CAD}$ are linked together. Moreover, Karan et al. [60] have found that there is a strong correlation between left main coronary artery stenosis (in patient 62 years old or above) and CAD in patient undergoing coronary artery bypass grafting and it can be implemented as a risk factor for CAD. In another investigation, Steinvil et al. [61] have studied CAD predominance in patient undergoing transcatheter aortic valve implantation. Their study reveals that unilateral and bilateral CAS are very common in patient undergoing transcatheter aortic valve implantation and aortic stenosis can be used as a risk factor for CAD. Rauramaa et al. [11] in a different research, have explored the relationship between cardiorespiratory fitness and CAS, preventing factors are investigated. They used IMT as a criterion and proved that inverse correlation exists between cardiorespiratory fitness and CAS.

In some case such as radiation-induced CA damage, external factors may lead to CAD. Gujral et al. [62] use IMT as marker and founded IMT in carotid is increased after RT (in order to treatment of head and neck cancer) may be a useful marker of radiation-induced carotid atherosclerosis. They had a review and stated that high level stork risk is associated with neck RT [63]. Also, they announced that other CAS risk factors such as smoking and chemotherapy have not obvious effect on increasement of carotid IMT after RT. In similar investigating, Yuan et al. [63], have studied risk factors of CAS progression in patient treated with RT for nasopharyngeal carcinoma. Their results showed patients with 45 years old or above, at least 9 years history of RT and have two or more cardiovascular risk factors (such as diabetes, hyperlipidemia and hypertension) are more prone to CAS. Also, Chang et al. [64] have explored the connection between head and neck cancer RT and CAS in 290 patients. They announced that the RT group had a significantly higher plaque score than the nonirradiated group. They suggested different RT strategy should be used for old patients and stroke preventing medication should be applied. Also chemotherapy which is used widely in concerns treatment may lead to CAD [63].

Also as measuring biochemical risk factors usually seems hard to do and time consuming. Some researchers such as Barreto-Neto et al. [65] implemented low ankle-brachial Index as intracranial atherosclerotic stenosis risk factors in patients with ischemic stroke. The showed intracranial atherosclerotic stenosis is highly and independently connected to low ankle-brachial Index and can be used as an acceptable CAD predictor.

CVD and CVA are strongly connected together. Also, non-CVD and even treatment methods which are applied for cure of CVD or non CVD may result in CAD. These risk factors are presented in table 4.

\section{Common risk factors}

There is a series of risk factors which are common between biochemical, biomechanical and CVD (and non-CVD and treatrelated) risk factors. Some of these risk factors are harmful to human health such as Tobacco smoking $[1,56,63]$ and some others are related to genetic $[42,55]$ or to body conditions such as senescence $[46,51,60,64]$ and cardiorespiratory fitness [63]. Cerebrovascular experts advise healthy life to patients whom are suspected to CAD because accumulation of risk factors jeopardize patient lives. CAD common risk factors are shown in table 5.

Biochemical risk factors cover many CAD risk factors. Some of them (such as high LDL concentration) are easy to measure and some others (such as interleukin-6) are not but among CAD biochemical risk factors, dyslipidemia (especially high LDL concentration) and high C-reactive protein concentration in blood are more common to determine CAD. Also CAD biomechanical and biochemical risk factors are closely linked together. Most famous CAD biomechanical risk factors is IMT and regularly is used by cerebrovascular experts

Table 4. CVD, non-CVD and treat-related risk factors.

\begin{tabular}{|l|l|}
\hline Researchers & CVD and Related disease \\
\hline Sobieszczyk [1] & Hypertension, hyperlipidemia and diabetes \\
\hline Joh et al. [51] & Hypertension \\
\hline Vouillarmet et al. [52] & Diabetes \\
\hline Strömberg et al. [53] & PR and plaque hemorrhage \\
\hline Teng et al. [54] & Plaque hemorrhage \\
\hline Razzouk et al. [55] & Having PAD, stroke or TIA experiences \\
\hline Steinvil et al. [57] & Extent of coronary atherosclerosis \\
\hline Rosa et al. [58] & Coronary artery diseases \\
\hline Iannaccone et al. [59] & $\begin{array}{l}\text { Large calcifications and fibrotic tissue AP, } \\
\text { Unsuccessful Stenting }\end{array}$ \\
\hline Karan et al. [60] & Undergoing coronary artery bypass grafting \\
\hline Steinvil et al. [61] & $\begin{array}{l}\text { Undergoing transcatheter aortic valve } \\
\text { implantation }\end{array}$ \\
\hline Gujral et al. [62] & Head and neck RT \\
\hline Gujral et al. [63] & Head and neck RT and chemotherapy \\
\hline Yuan et al. [64] & RT for nasopharyngeal carcinoma \\
\hline Chang et al. [65] & Head and neck RT \\
\hline Barreto-Neto $[66]$ & Low ankle-brachial Index \\
\hline
\end{tabular}


Table 5. Common risk factors.

\begin{tabular}{|l|l|}
\hline Researchers & Other Factors \\
\hline Sobieszczyk [1] & Tobacco smoking \\
\hline Rauramaa et al. [11] & Poor cardiorespiratory fitness \\
\hline Kakkos et al. [42] & Male gender \\
\hline Boulos et al. [46] & Old age \\
\hline Joh et al. [51] & Old age, tobacco smoking \\
\hline Razzouk et al. [55] & Male gender \\
\hline Karan et al. [60] & Old age \\
\hline Gujral et al. [63] & tobacco smoking \\
\hline Yuan et al. [64] & Old age \\
\hline
\end{tabular}

to determine CAD. Also, abnormal geometrical shapes of CA may be considered as CAD risk factor. In addition, CVD and non-CVD such as diabetes and hypertension is strictly associated with CAD and sometimes treatments approaches such as head and neck RT or endarterectomy may leads to CAD. Also, there is a fourth group of CAD risk factors that include health-related risk factors such as cardiorespiratory fitness and products which are containing harmful materials such as Tobacco. Also, general risk factors such as male gender and aging are included in this group.

\section{3-CAD and AP simulation}

Experimental and numerical simulation of cerebrovascular/ cardiovascular system makes it possible to understand their behaviors. It is feasible, coast effective and very safe way (especially numerical simulation) to study human cerebrovascular system in vitro. In many cases, researchers have tried to simulate human arteries (such as carotid bifurcation) to understand biomechanical behaviors of arteries and CVD or CVA. Some of scientists have acted hemodynamical studies out and some others have concentrated on atherosclerosis progression and its causes.

As mentioned before, biomechanical behavior of blood and arterial wall can explain procedure of atherosclerosis and determine atherogenic regions. In vivo experimental study of biomechanical behavior cardiovascular system due to limitation of device, complicatedshape arteries and in sometimes needing to invasive surgeries dose not seems cost effective and accurate. Also, in vitro experimental study is restricted by lake of realistic human body material and working conditions and these position implies oversimplification assumption. Only some studies such as done by Goubergrits et al. [48] have not applied oversimplification assumption in experimental investigation of CVA and other researchers have preferred to study cerebrovascular or cardiovascular systems numerically. FEM (or FEA) and finite volume method are common computational fluid dynamic methods and vastly have implemented $[5,13,17,66]$ for simulation of cardiovascular or cerebrovascular system.

\section{CA geometry}

Proposed numerical models by regarding arteries (or plaque) geometry accuracy can be categorized into realistic and simplified models. Also simplified geometry models can be 1) one and 2D) and 2) $3 \mathrm{D}$ but realistic model must be $3 \mathrm{D}$. Some researchers $[4,5,6,17,66]$ have selected simplified or idealized CA models for study. For instance, Long et al. [6] studied effects of severity and axisymmetrical/ asymmetrical properties of stenosis on post stenosis flow parameters (such as separation zones, WSS and velocity profile) in a 3D idealized CA. They reported that post stenotic separation zone (especially at diastolic phase) is very complicated. They announced severity of axisymmetric stenoses have greater influence on post stenotic area than asymmetrical stenoses and oscillatory WSS amplitude (which is existed in several downstream regions of stenosis) are strongly connected to location and severity of stenosis.

Whereas idealized and simplified geometries have been used for certain proposes but recently by progression in computer sciences, diagnostic devices and technics such as CT imaging, US and so on, cerebrovascular researchers prefer to study CVA and cerebrovascular system behavior realistically $[6,18,47,67]$. This trend is due to complex inherent nature of blood flow in carotid bifurcation artery and needing to more precise determination of biomechanical parameters.

\section{Blood viscosity effects}

Many numerical studies have been done in CA hemodynamic and among them, the most controversial mechanical property of blood seems viscosity. Some researchers have assumed blood as a Newtonian fluid in high shear rate $(>1001 / \mathrm{s})[68,69]$ and others have stated that due to existence of low shear rate regions (especially in complicatedgeometry arteries such as bifurcation and 3D curvatures) blood viscosity should be modeled as Non-Newtonian fluid. Razavi et al. [70] have studied effects of a Newtonian and six non-Newtonian viscosity models (power-law, generalized power-law, Carreau, CarreauYasuda, modified-Casson and Walburn-Schneck) on unsteady hemodynamics of 2D stenosed CA. They applied non-Newtonian GI Factor to determine whether non-Newtonian assumption is essential or not. They stated that GI=1 is an acceptable criterion cut off value for non-Newtonian behavior of blood in a stenosed artery. Their outputs revealed that power law and Walburn-Schneck models are way off real biomechanical behavior of blood within stenosed artery. Also, generalized power-law and modified Casson underestimates nonNewtonian behaviors. They have claimed that Carreau and CarreauYasuda are more accurate than other investigated models to simulate non-Newtonian behavior of blood flow in stenosed CA. In addition, they showed that as more carotid lumen size has been reduced, WSS values will be greater in throat region of stenosis, radial velocity will be more disturbed and larger RZ will be formed at downstream of stenosis. In another similar study, Pinto et al. [71] have explored the effects of hematocrit and number and severity of stenosis on hemodynamics parameters of a variable blood viscosity model within 1D flow flied in an overlapping stenosis analytically and numerically. Their simulation outputs demonstrated that height of stenosis or number of constrictions and hematocrit level are associated directly with pressure gradient force, flow velocity and the flow field impedance. In another study, Rabby et al. [72] have simulated blood flow $(\mathrm{Re}=300)$ within a 2D idealized blood vessel with axisymmetric stenosis to investigate outputs of Newtonian or non-Newtonian blood viscosity assumptions. They concluded non-Newtonian model selection leads to permanent laminar flow whereas by choosing Newtonian model, transient flow can be observed at the downstream of stenosis. Also, they reported high WSS at center of stenosis and RF (due to negative pressure gradient) at the downstream of stenosis.

\section{PM}

Hemodynamical parameters alteration after stenosis can be used as biomechanical CAD predictor and therefore many numerical studies have been conducted to find the relationship of PM and CVA. Dependency of atherosclerotic CA on PM and mechanical boundary conditions (such as pulsatile inlet) have been investigated frequently. Tian et al. [12] implemented a simplified 2D stenosed artery to study 
PM and flow conditions effects on artery mechanical stresses. They mentioned flow regime in healthy human arteries is often laminar and existence of asymmetric stenosis ends to increasement of WNS, WSS and its gradient. Also, they stated that height of stenosis role in flow alteration is more critical than its breadth and by elevating Re, flow shear rate and WNP increase and WSS decreases. In addition, they stated that Newtonian viscosity assumption leads to higher values of WNP, WSS and its gradient and only shear rate is higher in nonNewtonian viscosity model. Finally, they stated that oscillatory nature of WNS, shear rate, WSS and its gradients originated from pulsatile blood flow. Piskin and Celebi [73] have used CT for construction of realistic geometry of a patient with CAS. They perform a study to investigate different inlet velocity profile on hemodynamical features of CAS. They focused on critical regions of CA such as bifurcation and sinusoidal enlargement region of ICA and presented main mechanical parameters such as velocity, pressure and WSS. Their results indicates that hemodynamic parameters in CA with stenosis are sensitive to inlet boundary condition and relationships between biomechanical parameters and inlet velocity in CA is highly nonlinear. Pinto et al. [71] have used an open source numerical software to simulate pulsatile and elastic properties of blood in a simplified stenosed artery. Also, they solved governing equation analytically and compared numerical (Open Foam and ANSYS software) and analytical results. Their results were in good agreement in numerical and analytical solutions and showed that considering shear-thinning and pulsatile nature of blood (especially for arteries located in vicinity of heart) will lead to accurate results. Sousa et al. [18] have implemented US and Doppler velocity measuring to present a methodology for patient-specific hemodynamics study of the CA bifurcation. Their generated FEM results were in good agreement with those had been obtained from Doppler US. They reported complex flow field distal to stenosis and stated that WSS in stenosed $\mathrm{CA}$ is very higher than healthy CA during systolic phase. Also, they declared RZ is linked with low time-averaged WSS and high oscillating SI. Furthermore, they suggested FEM insist of US to obtain flow features where US is unable to determine flow parameters precisely such as irregular calcified AP and when blood velocity is so high. As existence of AP alters hemodynamical parameters, AP removal or arterial wall dilating technics such as endarterectomy [74] and stenting [59] changes atherosclerotic CA flow field. Recently, Guerciotti et al. [74] have comprised hemodynamics of CA in realistic cases, before and after endarterectomy. They acquired simulation base data from Echo-Color Doppler measurements. Their promising results showed that biomechanical properties of CA will be back to its healthy state after endarterectomy and patients whom used patch to close their arteriotomies are more prone to restenosis than whom patients with direct suture. Younis et al. [67] in a promising (a finite volume analysis) study, have investigated numerical parameters (temporal and spatial resolution) influence on blood flow field in a replica of stenosed CA. They mentioned that experimental have shown that even by applying steady inlet flow, flow field within CA is unsteady and chaotic and two unstable jets exist at ICA and ECA. This flow pattern almost cannot be seen in relatively accurate numerical simulation of diseased CA but by choosing adequate small time steps and grid size, can be gained. They indicated that choosing inappropriate temporal and spatial resolutions may lead to acceptable results but many critical feature of flow (such as chaotic behavior of blood flow within stenosed CA) remains concealed.

\section{Atherosclerotic CA flow regime}

Rarely did researchers investigate flow regime (laminar, transitional or turbulent) effect on CAD. Some of numerical researchers assumed that blood regime is laminar $[5,6,12]$ within CA but this assumption seems oversimplification especially for CAD patients. Lee et al. [34] have used realistic different inlet velocity profile city (obtained from color Doppler US) and carotid bifurcation geometry (extracted from CT imaging) to study flow regime in a stenosed CA. Their results revealed flow regime is transitional or weakly turbulent during systolic phase and laminar during diastolic phase in post-stenotic region of ICA. They indicated WSS of stenotic regions is higher than non stenotic ones and oscillatory RF and low pressure can be observed near stenosis of ICA. Also, they confirmed complex flow filed assumption inside stenosed CA. In another study, Gataulin et al. [75] have developed numerical and experimental (parameters are measured by Doppler US) models of an asymmetric stenosis (75\%) in a blood vessel to study flow regime. They realized that flow in a simple stenosed blood vessel is laminar if $\operatorname{Re}(\mathrm{Re})$ be under 300 and they advised semi-empirical k- $\omega$ shear stress transport turbulent model for swirling and non-swirling flow field with $\operatorname{Re}>300$. Also, they measured RF length at upstream and downstream of stenosis and stated that for $\mathrm{Re}>300$, RF length decreases and increases in symmetry plane of upstream and downstream of stenosis respectively.

\section{FSI analysis}

Regarding viscoelasticity of arterial wall and pulsatile nature of blood in CA, there is a mutual interaction between artery wall and blood. Many researchers have implemented FSI analysis in their numerical investigation in CAD scope. Lee et al. [13] have used a patient realistic CCA model with a mild stenosis and consider FSI to study relationship between CCA wall distensibility and different wall compliances (healthy and atherosclerotic CCA wall). Their numerical simulation have demonstrated that, even for mild stenosis, large flow separation, RZs with low WSS and high oscillatory SI values exist at post stenotic region of CCA and such flow field may cause further AP progression and enlargement. Also, they reported plaque shoulder experiences high WSS. In addition, they showed separation zone in healthy CCA is greater than atherosclerotic CCA and atherosclerotic artery, due to their nonhomogeneous composition (ordinary arterial wall and plaque components), experience non uniform stresses and plaques are more prone to rupture than arterial wall. Moreover, they reported that WSS and its time averaged values were generally lower and stresses in the wall were higher in the healthy artery. In another FSI study, Valencia and Baeza [66] have studied effect of pressure drop as boundary condition in two layer (hyperelastic and anisotropic) arterial wall model with symmetric stenosis on hemodynamic parameters. They chose realistic pressure drop as boundary conditions (insist of velocity) and stated this type of boundary condition results in lower velocity and WSS values at throat than those previously reported by other researchers at symmetric stenotic artery.

\section{LDL concentration}

LDL concentration have an unignorable role in formation of AP. Therefore, it seems wisely to consider LDL particles transport within arteries. Some researchers have added mass transfer equation to their calculations and have studied concentration of LDL particles within cardiovascular system. For instance, Nematollahi et al. [5] have investigated LDL surface concentration (as a risk factor of regions which are prone to $\mathrm{CAD}$ ) within a $2 \mathrm{D}$ stenosed (up to $60 \%$ ) CA under steady state condition and permeable wall assumption. Their outputs indicates that LDL surface concentration increases in regions associated with high infiltration rate (high blood pressure) and low WSS (such 
Table 6. CAD simulations.

\begin{tabular}{|c|c|c|}
\hline Researchers & Object & Outstanding Outcomes \\
\hline Riahi et al. [4] & $\begin{array}{l}\text { Study effects of hematocrit and } \\
\text { number and severity of stenosis } \\
\text { on hemodynamic parameters }\end{array}$ & $\begin{array}{l}\text { 1. Height of stenosis/number of constrictions and hematocrit level are associated directly with } \\
\text { pressure gradient force, flow velocity and the flow field impedance. }\end{array}$ \\
\hline Nematollahi et al. [5] & $\begin{array}{l}\text { Finding region with high LDL } \\
\text { surface concentration in CA } \\
\text { (steady flow) }\end{array}$ & LDL surface concentration increases in high infiltration rate and low WSS region \\
\hline Long et al. [6] & $\begin{array}{l}\text { Study effects of severity and } \\
\text { axisymmetrical/asymmetrical } \\
\text { properties of stenosis on post } \\
\text { stenosis flow parameters }\end{array}$ & $\begin{array}{l}\text { 1. High influence of severity of axisymmetric stenoses on post stenotic area. } \\
\text { 2. Existence of strong correlation between oscillatory WSS amplitude and location and severity of } \\
\text { stenosis. }\end{array}$ \\
\hline Tomaso et al. [9] & $\begin{array}{l}\text { Introducing a promising outline } \\
\text { (figure } 2 \text { ) for determination of } \\
\text { patient specific plaque growth } \\
\text { simulation }\end{array}$ & $\begin{array}{l}\text { 1. Low WSS and blood velocity are associated with increment in endothelial cells permeability and } \\
\text { reactions and plaque formation regions. } \\
\text { 2. Proposed model is able to determine time of AP formation. }\end{array}$ \\
\hline Tian et al. [12] & $\begin{array}{l}\text { Study PM and flow conditions effects on } \\
\text { resulting stresses }\end{array}$ & $\begin{array}{l}\text { 1. Flow regime in healthy humans is often laminar. } \\
\text { 2. One side AP ends to increasement of WNS, WSS and its gradient. } \\
\text { 3. Height of stenosis is more critical than its breadth. } \\
\text { 4. Newtonian viscosity assumption leads to higher values of WNP, WSS and its gradient and lower } \\
\text { shear rates. }\end{array}$ \\
\hline Lee et al. [13] & $\begin{array}{l}\text { Study relationship between } \\
\text { CCA wall distensibility and } \\
\text { different wall compliances in } \\
\text { stenotic CCA }\end{array}$ & $\begin{array}{l}\text { 1. Even for mild stenosis, large flow separation RZs with low WSS and high oscillatory SI values } \\
\text { exist at post stenotic region of CCA. } \\
\text { 2. Plaque shoulder experiences high WSS. }\end{array}$ \\
\hline Fazli et al. [17] & $\begin{array}{l}\text { Finding region with high LDL } \\
\text { surface concentration in CCA } \\
\text { (unsteady flow) }\end{array}$ & $\begin{array}{l}\text { 1. There is a linear relationship between infiltration velocity of endothelial layer and LDL surface } \\
\text { concentration. } \\
\text { 2. Maximum LDL surface concentration occurs immediately after the separation point and LDL } \\
\text { surface concentration decreased as the recirculation length is increased. }\end{array}$ \\
\hline Sousa et al. [18] & $\begin{array}{l}\text { Present a methodology for } \\
\text { patient-specific hemodynamics } \\
\text { study of the CA bifurcation }\end{array}$ & $\begin{array}{l}\text { 1. } \mathrm{RZ} \text { is linked with low time averaged WSS and high oscillating SI } \\
\text { 2. } \mathrm{WSS} \text { in stenosed carotid is very higher than healthy carotid during systolic phase }\end{array}$ \\
\hline Lee et al. [34] & $\begin{array}{l}\text { Study flow regime in a stenosed } \\
\text { CA }\end{array}$ & $\begin{array}{l}\text { 1. Flow regime is transitional or weakly turbulent during systolic phase and laminar during diastolic } \\
\text { phase in post-stenotic region of ICA. } \\
\text { 2. Oscillatory RF and low pressure can be observed near stenosis of ICA. }\end{array}$ \\
\hline Valencia and Baeza [67] & $\begin{array}{l}\text { Investigate effect of pressure drop as } \\
\text { boundary condition on hemodynamic } \\
\text { parameters in stenosed artery }\end{array}$ & 1. Pressure drop boundary condition results in lower velocities and WSS values at throat. \\
\hline Younis et al. [68] & $\begin{array}{l}\text { Study temporal and spatial resolution } \\
\text { parameters influence on flow field in a } \\
\text { replica of stenosed CA }\end{array}$ & $\begin{array}{l}\text { 1. Even by applying steady inlet flow, flow field within CA is unsteady and chaotic and two unstable } \\
\text { jets exist at ICA and ECA. } \\
\text { 2. Insufficient temporal and spatial resolution lead to veiling criticalbiomechanicalparameters }\end{array}$ \\
\hline Razavi et al. [71] & $\begin{array}{l}\text { Selecting best viscosity model } \\
\text { on unsteady hemodynamics of } \\
\text { 2D stenosed CA }\end{array}$ & $\begin{array}{l}\text { 1. Carreau and Carreau-Yasuda are more accurate than other investigated models. } \\
\text { 2. GI=1 indicts cut off value for non-Newtonian behavior of blood in astenosed artery. }\end{array}$ \\
\hline Pinto et al. [72] & $\begin{array}{l}\text { Simulation of pulsatile and elastic } \\
\text { properties of blood in a simplified } \\
\text { stenosed artery }\end{array}$ & 1. Shear-thinning and pulsatile nature of blood should be consider in numerical simulation \\
\hline Rabby et al. [73] & $\begin{array}{l}\text { Investigation of flow behavior by } \\
\text { Newtonian/non-Newtonian blood } \\
\text { viscosity assumptions within } \\
\text { axisymmetric stenosis }\end{array}$ & $\begin{array}{l}\text { 1. Only by choosing Newtonian model, transient flow can be observed at the downstream of stenosis. } \\
\text { 2. There is high WSS and RF at center and downstream of stenosis respectively. }\end{array}$ \\
\hline Piskin and Celebi [74] & $\begin{array}{l}\text { Inlet velocity profile altering } \\
\text { effects on hemodynamical } \\
\text { features of CAS }\end{array}$ & 1. Highly nonlinear relationship between inlet velocity and biomechanical parameters in CA. \\
\hline Guerciotti et al. [75] & $\begin{array}{l}\text { Hemodynamic parameter } \\
\text { alteration after endarterectomy }\end{array}$ & $\begin{array}{l}\text { 1. Biomechanical properties of CA will back to its healthy state after endarterectomy } \\
\text { 2. To prevent CAS regression, direct suture should be done instead of using patch }\end{array}$ \\
\hline Gataulin et al. [76] & $\begin{array}{l}\text { Study flow regime of an } \\
\text { asymmetric stenosis }(\% 75) \text { in a } \\
\text { straight blood vessel }\end{array}$ & $\begin{array}{l}\text { 1. Laminar Flow for } \operatorname{Re}<300 \\
\text { 2. } \mathrm{RF} \text { length decreases and increases in symmetry plane of upstream and downstream of stenosis } \\
\text { respectively. }\end{array}$ \\
\hline
\end{tabular}

as separation and reattachment points). Also, they suggested nonNewtonian viscosity model for blood flow modelling in carotid arteries (because of Newtonian incapability of Newtonian viscosity model to determine increment in LDL surface concentration at reattachment points). In similar study, Fazli et al. [17] have studied Nematollahi and his coauthors' investigation [5] under unsteady condition at CCA. Their results confirmed previous studies suggesting low WSS regions as atherogenic. Also, they have found a linear relationship between infiltration velocity of endothelial layer and LDL surface concentration which supports considering high blood pressure as an atherosclerosis risk factor. They mentioned maximum LDL surface concentration occurs immediately after the separation point and LDL surface concentration decreased as the recirculation length is increased.

Although researchers have been simulated different aspects of CAD but it is obvious that model which consider biochemical and biomechanical aspects of atherosclerosis disease coincidently are more accurate. In novel approach, Tomaso et al. [9] combined experimental and numerical methods of biomechanical and biochemical 
atherosclerosis progression modeling and have introduced a promising outline (Figure 2) for determining of (even long term) patient specific plaque growth simulation.

As stated by Tomaso et al. [9], the yellow colored boxes are the patient-specific hemodynamics, the orange colored boxes are the LDL related behavior/processes and the green colored boxes states the monocyte macrophage behavior. The starting process (hemodynamics) and the ending process (foam cell formation) are shown by grey color boxes. The arrows between boxes are an exchange of information from one box (output) to another box (input). They used realistic geometry and boundary condition obtained from multi-Slice CT angiograms and Doppler echocardiography respectively. Also, by using a modular and parallelizable model, they simulated biochemical and transport (such as sub-cellular or molecular) processes of atherosclerosis. Their results demonstrated that where WSS and blood velocity magnitude are low, endothelial cells permeability and their reactions increase and plaque formation initiates from such regions. They also were able to determine time of AP (for studied case it was 16 years and 11 months) formation. They reported that their results were in excellent agreement with clinical data.

Numerical and experimental simulation reviewed articles are summarized in table 6 .

\section{Conclusion}

$\mathrm{CAD}$ are one of most prevalence CVA and takes many lives yearly. Many researches have been conducted to understand CAS formation, progression and regression. In current review, 77 selected articles (which were related to $\mathrm{CAD}$ ) have been summarized to present a comprehensive and succinct source for further CAD scope studies. This review has been done to fill the gap existed between CAD aspects. Selected articles categorized to three man groups: CAD diagnosis, risk factors and simulation.

CAD diagnosis methods were divided to hemodynamics-based,

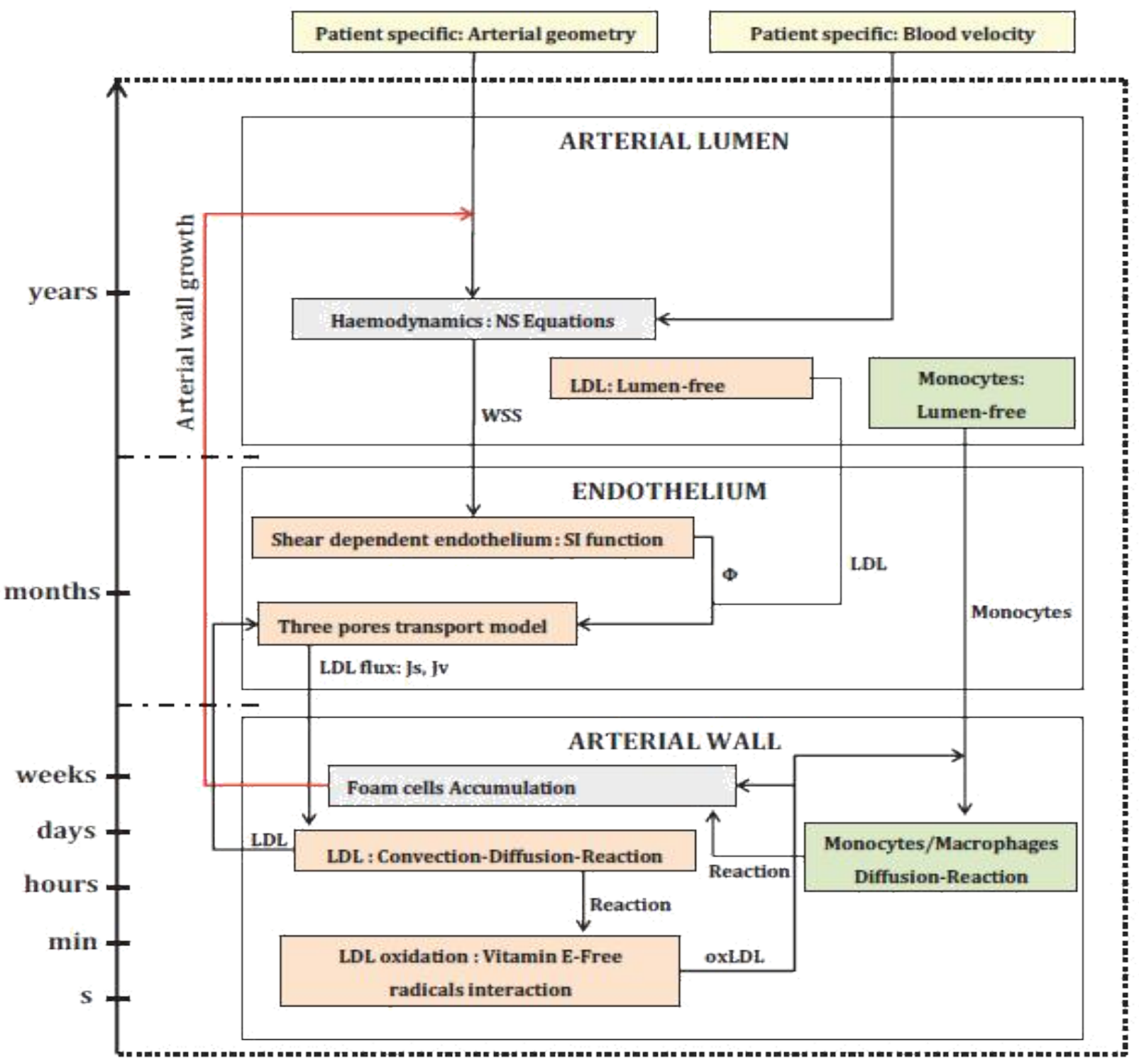

Temporal Scale

Figure 2. Workflow of the atherosclerosis remodeling cycle by Tomaso et al. [9]. 
elasticity-based, PM-based and other diagnostic methods. Most of CVA researchers preferred to use US techniques to detect CAS and among US methods, PDI have been introduced as most cost effective technique. Beside US method, MRI, LDA, mechanical and microscopic tests have been implemented by researchers to CAD diagnosis and AP detection.

CAD risk factors presented in current study cover biochemical, biomechanical, CVD (non-CVD and treat-related) CAD risk factors. High Concentration of LDL (and dyslipidemia) and high values of NLR, interleukin-6, tumor necrosis factor-alpha, hs-CRP, Glycohemoglobin, PLR, Lp-PLA2 have been introduced as CAD biochemical risk factors. Most common CAD biochemical risk factor is high Concentration LDL which assumed to trigger AP formation processes. CAD biomechanical risk factors are usually related to shape of CA. IMT is implemented vastly in CAD diagnosis and known as accepted CAD risk factor. Other risk factors such as abnormal curvature and hemodynamical parameters can be sign of CAD. Moreover, PAD and some prevalence diseases such as diabetes or hypertension have been introduced as CAD risk factors. Also, sometime treatment methods such as head and neck $\mathrm{RT}$ or chemotherapy may induce CAD. Beside mentioned risk factors, there are some risk factors which are common among most CAD patient. These risk factors are related to human genetic such as male gender or to general health such as tobacco smoking, cardiorespiratory fitness and age. Increment in numbers of CAD risk factors should be noted and preventive action such as diet or medication should be applied.

Numerical and experimental CAD simulation have been done by biomechanical experts to study CAD formation or progression. CAD in vivo experimental study, due to important role and location of CA, is so hard and in vitro experimental study usually suffers from lake of exact human body material and work conditions and therefore, many researcher have attempt to simulate CA numerically. CAD numerical studies have revealed that AP location are associated with low and oscillatory WSS, RZ and high LDL concentration.

This review showed that CAD is a multi-aspects disease and only by considering of all CAD aspects, a comprehensive sight can be obtained. It seems that collaboration of different scopes of CAD can lead to outstanding results for conquering $\mathrm{CAD}$. Some researchers have been realized this issue and have attempted to use all CAD aspects together. Also, realistic data should be implemented to achieve accurate data. Rarely did researchers pay attention to head and neck position or peripheral tissue loads effects on CAD and these factors could be considered in further studies.

\section{References}

1. Sobieszczyk P, Beckman J (2006) Carotid artery disease. Circulation 114: e244-247. [Crossref]

2. Chaturvedi S, Sacco RL (2015) "How Recent Data Have Impacted the Treatment of Internal Carotid Artery Stenosis”. J Am Coll Cardiol 65: 1134-1143. [Crossref]

3. Petty GW, Brown RD, Whisnant JP, Sicks JD, Michael O'Fallon W, et al. (1999) Ischemic Stroke Subtypes A Population-Based Study of Incidence and Risk Factors. Stroke 30: 2513-2516. [Crossref]

4. Younis BA, Spring S, Olaf Neumann S, Weigand B (2007) "Simulation of flow in an exact replica of a diseased human carotid artery". Applied Mathematical Modelling 31: 2599-2609.

5. Nematollahi A, Shirani E, Mirzaee I, Sadeghi MR (2012) "Numerical simulation of LDL particles mass transport in human carotid artery under steady state conditions". Scientia Iranica 19: 519-524.

6. Long Q, Xu XY, Ramnarine KV, Hoskins P (2001) "Numerical investigation of physiologically realistic pulsatile flow through arterial stenosis". J Biomech 34: 12291242 .
7. Fan J, Watanabe $\mathrm{T}$ (2003) Inflammatory reactions in the pathogenesis of atherosclerosis. $J$ Atheroscler Thromb 10: 63-71. [Crossref]

8. Osterud B, Bjorklid E (2003) Role of monocytes in atherogenesis. Physiol Rev 83: 1069-1112. [Crossref]

9. Tomaso GD, Pichardo-Almarza C, Agu O, Díaz-Zuccarini V (2015) “A Multiscale and Patient-Specific Computational Framework of Atherosclerosis Formation and Progression: A Case Study in the Aorta and Peripheral Arteries". Procedia Computer Science 51: 1118-1127.

10. Pandya A, Gupta A (2016) "Improving imaging to optimize screening strategies for carotid artery stenosis". Clin Imaging 40: 276-278. [Crossref]

11. Rauramaa R, Rankinen T, Tuomainen P, Väisänen S, Mercuri M (1995) "Inverse relationship between cardiorespiratory fitness and carotid atherosclerosis". Atherosclerosis 112: 213-221. [Crossref]

12. Tian FB, Zhu L, Fok PW, Lu XY (2013) Simulation of a pulsatile non-Newtonian flow past a stenosed 2D artery with atherosclerosis. Comput Biol Med 43: 1098-1113. [Crossref]

13. Lee KW, Wood NB, Xu XY (2004) "Ultrasound image-based computer model of a common carotid artery with a plaque". Med Eng Phys 26: 823-840. [Crossref]

14. Bluth EI (2003) "Screening Test for Carotid Disease". Seminars in Ultrasound, CT and MRI 24: 55-61.

15. den Hartog AG, Bovens SM, Koning W, Hendrikse J, Luijten PR, et al. (2013) Current Status of Clinical Magnetic Resonance Imold age for Plaque Characterisation in Patients with Carotid Artery Stenosis. Eur J Vasc Endovasc Surg 45: 7-21. [Crossref]

16. Sidhu PS, Allan PL (1997) Ultrasound Assessment of Internal Carotid Artery Stenosis Clin Radiol 52: 654-658. [Crossref]

17. Fazli S, Shirani E, Sadeghi MR (2011) "Numerical simulation of LDL mass transfer in a common carotid artery under pulsatile flows". J Biomech 44: 68-76. [Crossref]

18. Sousa LC, Castro CF, António CC, Sousa F, Santos R, et al. (2016) Computational simulation of carotid stenosis and flow dynamics based on patient ultrasound data - A new tool for risk assessment and surgical planning. Adv Med Sci 61:32-39. [Crossref]

19. Steinbuch J, Hoeks AP, Hermeling E, Truijman MT, Schreuder FH, et al. (2016) Standard B-Mode Ultrasound Measures Local Carotid Artery Characteristics as Reliably as Radiofrequency Phase Tracking in Symptomatic Carotid Artery Patients. Ultrasound Med Biol 42: 586-595. [Crossref]

20. Sakamoto Y, Sato K, Kobayashi J, Koga M, Nagatsuka K, et al. (2016) Peak Systolic Velocity Measured by Continuous-Wave Doppler Ultrasonography without Angle Correction in Patients with Internal Carotid Artery Stenosis. J Stroke Cerebrovasc Dis 25: 1355-9. [Crossref]

21. Tokunaga K, Koga M, Yoshimura S, Arihiro S, Suzuki R, et al. (2016) Optima Peak Systolic Velocity Thresholds for Determineing Internal Carotid Artery Stenosis Greater than or Equal to $50 \%, 60 \%, 70 \%$, and $80 \%$ Keisuke. J Stroke Cerebrovasc Dis 25: 921-926. [Crossref]

22. Masuda M, Emoto T, Suzuki A, Akutagawa M, Kitawaki T, et al. (2013) Evaluation of blood flow velocity waveform in common carotid arteryusing multi-branched arterial segment model of human arteries. Biomedical Signal Processing and Control 8: 509519 .

23. Poepping TL, Rankin RN, Holdsworth DW (2010) Flow patterns in carotid bifurcation models using pulsed Doppler ultrasound: effect of concentric vs. eccentric stenosis on turbulence and recirculation. Ultrasound Med Biol 36: 1125-1134. [Crossref]

24. Sander D, Schulze-Horn C, Bickel H, Gnahn H, Bartels E, et al. (2006) Combined effects of hemoglobin A1c and C-reactive protein on the progression of subclinical carotid atherosclerosis: the INVADE study. Stroke 37: 351-357. [Crossref]

25. Huang C, Su Y, Zhang H, Qian LX, Luo J (2016) Comparison of Different Pulse Waveforms for Local Pulse Wave Velocity Measurement in Healthy and Hypertensive Common Carotid Arteries in Vivo. Ultrasound Med Biol 42: 1111-1123. [Crossref]

26. Kamenskiy AV, Dzenis YA, MacTaggart JN, Lynch TG, Jaffar Kazmi SA, et al. (2012) Nonlinear Mechanical Behavior of the Human Common, External, and Internal Carotid Arteries In Vivo. J Surg Res 176: 329-336. [Crossref]

27. Golematia S, Lehareas S, Tsiaparas NN, Nikita KS, Chatziioannou A, et al. (2015) Ultrasound-image-based texture variability along the carotid artery wall in asymptomatic subjects with low and high stenosis severitys: unveiling morphological phenomena of the vulnerable tissue. Physics Procedia 70: 1208 - 1211.

28. Nieuwstadt A, Fekkes S, Hansen HHG, de Korte CL, van der Lugt A, et al. (2015) Carotid plaque elasticity estimation using ultrasound elastography, MRI, and inverse 
FEA - A numerical feasibility study. Med Eng Phys 37: 801-807H. [Crossref]

29. Chai CK, Akyildiz AC, Speelman L, Gijsen FJ, Oomens CW, et al. (2015) Local anisotropic mechanical properties of human carotid atherosclerotic plaques Characterisation by micro-indentation and inverse finite element analysis. $J$ Mech Behav Biomed Mater 43: 59-68. [Crossref]

30. Barrett HE, Cunnane EM, Kavanagh EG, Walsh MT (2016) On the effect of calcification volume and configuration on the mechanical behaviour of carotid plaque tissue. J Mech Behav Biomed Mater 56: 45-56. [Crossref]

31. Heiland VM, Forsell C, Roy J, Hedin U, Gasser TC (2013) Identification of carotid plaque tissue properties using an experimental-numerical approach. $J$ Mech Behav Biomed Mater 27: 226 -238. [Crossref]

32. Xiao H, Avolio A, Huang D (2016) A novel method of artery stenosis diagnosis using transfer function and support vector machine based on transmission line model: A numerical simulation and validation study. Comput Methods Programs Biomed 129: 71-81. [Crossref]

33. Bonanno L, Marino S, Bramanti P, Sottile F (2015) Validation of a computer-aided diagnosis system for the automatic identification of carotid atherosclerosis. Ultrasound Med Biol 41: 509-516. [Crossref]

34. Lee SE, Lee SW, Fischer PF, Bassiouny HS, Loth F (2008) Direct numerical simulation of transitional flow in a stenosed carotid bifurcation". J Biomech 41: 2551-2561. [Crossref]

35. Park YM, Koh KK, Han SH, Yu SH, Kang WC (2011) Carotid plaque to determine the presence of coronary artery stenosis in a patient with extremely low LDL-C. Int $J$ Cardiol 153: e3-e4. [Crossref]

36. Amor AJ, Catalan M, Pérez A, Herreras Z, Pinyol M, et al. (2016) Nuclear magnetic resonance lipoprotein abnormalities in newly-diagnosed type 2 diabetes and their association with preclinical carotid atherosclerosis. Atherosclerosis 247: 161-169. [Crossref]

37. Huang X, Wang A, Liu X, Chen S, Zhu Y, et al. (2016) Association between high sensitivity C-Reactive protein and prevalence of asymptomatic carotid artery stenosis. Atherosclerosis 246: 44e49. [Crossref]

38. Hyun S, Kwon S, Cho S, Park S, Jung W, et al. (2015) Can the Neutrophil-toLymphocyte Ratio Appropriately Determine Carotid Artery Stenosis in Patients with Ischemic Stroke?-A Retrospective Study. J Stroke Cerebrovasc Dis 24: 2646- 265. [Crossref]

39. Köklü E, Yüksel İÖ, Arslan S, Bayar N, Cağırcı G, et al. (2016) Is Elevated Neutrophilto-Lymphocyte Ratio a Risk factor of Stroke in Patients with Intermediate Carotid Artery Stenosis? J Stroke Cerebrovasc Dis 25: 578-584. [Crossref]

40. Varım C, Varım P, Acar BA, Vatan MB, Uyanık MS, et al. (2016) Usefulness of the platelet-to-lymphocyte ratio in determineing the severity of carotid artery stenosis in patients undergoing carotid angiography. Kaohsiung J Med Sci 32: 86-90. [Crossref]

41. Sarlon-Bartoli G, Boudes A, Buffat C, Bartoli MA, Piercecchi-Marti MD, et al. (2012) Circulating Lipoprotein-associated Phospholipase A2 in High-grade Carotid Stenosis: A New Biochemical risk factors for Determining Unstable Plaque. European Journal of Vascular and Endovascular Surgery 43: 154-159.

42. Kakkos SK, Nicolaides AN, Charalambous I, Thomas D, Giannopoulos A, et al. (2014) Risk factors and clinical significance of progression or regression of asymptomatic carotid stenosis. Journal of Vascular Surgery 59: 956-967.

43. Gallo D, Steinman DA, Morbiducci U (2016) Insights into the co-localization of magnitude-based versus direction-based indicators of disturbed shear at the carotid bifurcation. J Biomech. [Crossref]

44. Zhang C, Xie S, Li S, Pu F, Deng X, et al. (2012) Flow patterns and wall shear stress distribution in human internal carotid arteries: The geometric effect on the risk for stenoses. J Biomech 45: 83-89. [Crossref]

45. Gnasso A, Irace C, Mattioli PL, Pujia A (1996) Carotid intima-media thickness and coronary heart disease risk factors". Atherosclerosis 119: 7-15. [Crossref]

46. Boulos NM, Gardin JM, Malik S, Postley J, Wong ND (2016) Carotid Plaque Characterization, Stenosis, and Intima-Media Thickness According to Age and Gender in a Large Registry Cohort. Am J Cardiol 117: 1185-1191. [Crossref]

47. David Spence J (2008) The importance of distinguishing between diffuse carotid intima-media thickening and focal plaque. Canadian Journal of Cardiology 24: 61C-64C.

48. Goubergrits L, Affeld K, Fernandez-Britto J, Falcon L (2001) Atherosclerosis in the Human Common Carotid Artery. A Morphometric Study of 31 Specimens. Pathol Res

\section{Pract 197: 803-809. [Crossref]}

49. Sharifi A, Niazmand H (2015) Analysis of flow and LDL concentration polarization in siphon of internal carotid artery: Non-Newtonian effects. Comput Biol Med 65: 93-102. [Crossref]

50. Massai D, Soloperto G, Gallo D, Xu XY, Morbiducci U (2012) Shear-induced platelet activation and its relationship with blood flow topology in a numerical model of stenosed carotid bifurcation. European Journal of Mechanics - B/Fluids 35: 92-101.

51. Joh JH (2015) The Prevalence and Risk Factors for Atherosclerotic Carotid Stenosis and Carotid Plaque: A Community-Based Screening Study. Journal of Vascular Surgery 61: 91S-92S.

52. Vouillarmet J, Helfre M, Maucort-Boulch D, Riche B, Thivolet C, et al. (2016) Carotid atherosclerosis progression and cerebrovascular events in patients with diabetes. $J$ Diabetes Complications 30: 638-643. [Crossref]

53. Strömberg S, Nordanstig A, Bentzel T, Österberg K, Bergström GM (2015) Risk of Early Recurrent Stroke in Symptomatic Carotid Stenosis. Eur J Vasc Endovasc Surg 49: 137-144. [Crossref]

54. Teng Z, Sadat U, Brown AJ, Gillard JH (2014) Plaque hemorrhage in carotid artery disease: Pathogenesis, clinical and biomechanical considerations. J Biomech 47: 847 858. [Crossref]

55. Razzouk L, Rockman CB, Patel MR, Guo Y, Adelman MA, et al. (2015) Co-existence of vascular disease in different arterial beds: Peripheral artery disease and carotid artery stenosis - Data from Life Line Screening. Atherosclerosis 241: 687-691. [Crossref]

56. Alexandrova NA, Gibson WC, Norris JW, Maggisano R (1996) Carotid artery stenosis vascular disease in peripheral. J Vasc Surg 23: 645-649. [Crossref]

57. Steinvil A, Sadeh B, Arbel Y, Justo D, Belei A, et al. (2011) Prevalence and Risk factors of Concomitant Carotid and Coronary Artery Atherosclerotic Disease. Journal of the American College of Cardiology 57: 779-783.

58. Pereira da Rosa M, Portal VL (2011) Carotid stenosis and coronary artery bypass grafting. Revista da Associação Médica Brasileira 57: 317-321.

59. Iannaccone F, Debusschere N, De Bock S, De Beule M, Van Loo D (2014) The influence of vascular anatomy on carotid artery stenting: A parametric study for damage assessment. J Biomech 47: 890-898. [Crossref]

60. Karan R, Panic D, Obrenovic-Kircanski B, Kovacevic-Kostic N, Velinovic M, et al Risk factors of asymtomatic hemodynamically significant carotid stenosis in patients undergoing coronary artery bypass grafting. Clinical and Experimental Circulation 4AP5-9.

61. Steinvil A, Leshem-Rubinow E, Abramowitz Y, Shacham Y, Arbel Y, et al. (2014) Prevalence and Risk factors of Carotid Artery Stenosis in Patients With Severe Aortic Stenosis Undergoing Transcatheter Aortic Valve Implantation. Catheter Cardiovasc Interv 84:1007-1012. [Crossref]

62. Gujral DM, Shah BN, Chahal NS, Bhattacharyya S, Hooper J, et al. (2016) Carotid intima-medial thickness as a marker of radiation-induced carotid atherosclerosis. Radiother Oncol 118: 323-329. [Crossref]

63. Yuan C, Wu VW, Yip SP, Kwong DL, Ying M (2014) Predictors of the extent of carotid atherosclerosis in patients treated with radiotherapy for nasopharyngeal carcinoma. Plos One 9: e116284.

64. Chang YJ, Chang TC, Lee TH, Ryu SJ (2009) Risk factors of carotid artery stenosis after radiotherapy for head and neck cancers. Journal of Vascular Surgery 50: 280-285.

65. Barreto-Neto N, Barros AD, Jesus PA, Reis CC, Jesus ML, et al. (2016) Low Ankle-Brachial Index is a Simple Physical Exam Sign Determineing Intracranial Atherosclerotic Stenosis in Ischemic Stroke Patients. J Stroke Cerebrovasc Dis 25: 1417-20.

66. Valencia A, Baeza F (2009) Numerical simulation of fluid-structure interaction in stenotic arteries considering two layer nonlinear anisotropic structural model International Communications in Heat and Mass Transfer 36: 137-142.

67. Younis BA, Spring S, Olaf Neumann S, Weigand B (2007) Simulation of flow in an exact replica of a diseased human carotid artery. Applied Mathematical Modelling 31: 2599-2609.

68. Cho YI, Kensey KR (1991) Effects of the non-Newtonian viscosity of blood on flows in a diseased arterial vessel. Part 1: Steady flows. Biorheology 28: 241-262. [Crossref]

69. Pedley TJ (1980) The Fluid Mechanics of Large Blood Vessels. Cambridge University Press, 1980, Cambridge.

70. Razavi A, Shirani E, Sadeghi MR (2011) Numerical simulation of blood pulsatile flow 
in a stenosed carotid artery using different rheological models. $J$ Biomech 44: 20212030. [Crossref]

71. Pinto SIS, Doutel E, Campos JBLM, Miranda JM (2013) Blood Analog Fluid Flow in Vessels with Stenosis: Development of an Openfoam Code to Simulate Pulsatile Flow and Elasticity of the Fluid. APCBEE Procedia 7: 73-79.

72. Rabby MG, Razzak A, Mamun Molla Md (2013) Pulsatile non-Newtonian blood flow through a model of arterial stenosis. Procedia Engineering 56: 225-231.

73. Piskin S, Celebi MS (2013) Analysis of the effects of different pulsatile inlet profiles on the hemodynamical properties of blood flow in patient specific carotid artery with stenosis. Computers in Biology and Medicine 43: 717-728.

74. Guerciotti B, Vergara C, Azzimonti L, Forzenigo L, Buora A, et al. (2016) Computational study of the fluid-dynamics in carotids before and after end arterectomy. J Biomech 49: 26-38.

75. Gataulin YA, Zaitsev DK, Smirnov EM, Fedorova EA, Yukhnev AD (2016) Weakly swirling Bow in a model of blood vessel with stenosis: numerical and experimental study. St. Petersburg Polytechnical University Journal: Physics and Mathematics, In Press, Corrected Proof, Available online 14 March 2016.

Copyright: $\odot 2016$ Khakpour S. This is an open-access article distributed under the terms of the Creative Commons Attribution License, which permits unrestricted use, distribution, and reproduction in any medium, provided the original author and source are credited. 